\title{
Physical work environment risk factors for long term sickness absence: prospective findings among a cohort of 5357 employees in Denmark
}

Thomas Lund, Merete Labriola, Karl Bang Christensen, Ute Bültmann, Ebbe Villadsen

\begin{abstract}
Objectives To examine the effects of physical work environment on long term sickness absence and to investigate interaction between physical and psychosocial risk factors. Design and setting Prospective cohort study of long term sickness absence among employees in Denmark. Participants 5357 employees interviewed in 2000 about their physical work environment, and various covariates were followed for 18 months in a national sickness absence register. Outcome measurements Cox regression analysis was performed to assess risk estimates for physical risk factors in the work environment and onset of long term sickness absence, defined as receiving sickness absence compensation for eight consecutive weeks or more.

Results 348 participants (6.9\%) developed long term sickness absence during follow-up. Of these, 194 (55.7\%) were women and $154(44.3 \%)$ were men. For both female and male employees, risk of onset of long term sickness absence was increased by extreme bending or twisting of the neck or back, working mainly standing or squatting, lifting or carrying loads, and pushing or pulling loads. Significant interactions were found for three combinations of physical and psychosocial work environment risk factors among female employees $(\mathrm{P}<0.05)$.

Conclusion Uncomfortable working positions, lifting or carrying loads, and pushing or pulling loads increased the risk of onset of long term sickness absence. The study shows a potential for reducing long term sickness absence through modifying work postures straining the neck and back, reducing the risk of work done standing or walking, and reducing the risk associated with handling loads. Dealing with psychosocial stressors simultaneously may improve physical intervention efforts further for female employees.
\end{abstract}

\section{Introduction}

Sickness absence is caused by various different factors, including work environment exposures. ${ }^{12}$ In most of the literature on sickness absence, the outcome is short term sickness absence, or no distinction is made between short term and long term absence. There is reason to believe that short and long term sickness absence have different causes. ${ }^{3}$ To date, few studies have specifically addressed the problem of long term sickness absence, although the need for more knowledge is emphasised by the political and scientific communities. ${ }^{4-7}$

From a recent literature review it seems reasonable to conclude that documentation exists for the association between at least some physical exposures in the work environment and sickness absence. ${ }^{2}$ Ergonomic conditions-for example, uncomfortable working conditions such as heavy physical work, monotonous movements, and high physical demands-were found to be associated with different definitions of sickness absence. $^{8-12}$

Physical and psychosocial exposures coexist and are likely to interact in the work environment. Interventions aiming at the physical dimension of work might therefore obtain added value when simultaneously addressing the psychosocial dimension, and vice versa. However, only a few recent studies have analysed the effects of psychosocial and physical exposures simultaneously in relation to sickness absence. ${ }^{9} 1314$

According to a recent review of factors influencing sickness absence, much of the research has severe design deficiencies with regard to insufficient control for confounders and the use of cross sectional designs. ${ }^{2}$ In this longitudinal cohort study, we investigated associations between physical exposures in the work environment and the onset of long term sickness absence among Danish employees, taking into account demographic factors, chronic disease, psychosocial risk factors in the work environment, and health behaviour. We also investigated possible interactions between physical and psychosocial risk factors in the work environment.

\section{Method}

\section{Population}

This study is part of the project DWECS/DREAM, which is based on a merger between the Danish work environment cohort study (DWECS) and a national register on social transfer payments (DREAM). DWECS features a random sample of 11437 people living in Denmark, of which $8583(75 \%)$ participated in interviews. Of these 5357 were aged 18-64 and had worked as employees for at least two months before the baseline interview. This interview took place in 2000 and assessed work environment exposures, age, sex, education, family status, chronic disease, and health behaviour. ${ }^{15}$ The cohort was followed up in the DREAM register from 1 January 2001 to 30 June 2002. DREAM contains weekly information on granted sickness absence compensation for all citizens in Denmark. ${ }^{16}$ Sickness absence compensation is given to the employer, who can apply for a refund from the state for employees after two weeks of sickness absence.

We included 5033 people (93.9\%) without missing values on baseline risk factor variables in the study: $2446(48.6 \%)$ women and 2587 men (51.4\%). They were followed in DREAM for 78 
Table 1 Mean and median of scores on five physical risk factor indices (index score range 0-100)

\begin{tabular}{|c|c|c|c|c|}
\hline \multirow{2}{*}{ Risk factor index } & \multicolumn{2}{|c|}{ Female employees $(n=2446)$} & \multicolumn{2}{|c|}{ Male employees $(n=2587)$} \\
\hline & Mean & Median & Mean & Median \\
\hline Extreme bending or twisting of neck or back & 13.6 & 4.8 & 12.7 & 4.8 \\
\hline Working with arms lifted or hands twisted & 9.7 & 3.6 & 11.8 & 3.6 \\
\hline Working mainly standing or squatting & 22.5 & 15.6 & 23.5 & 15.6 \\
\hline Lifting or carrying loads & 14.0 & 8.4 & 18.7 & 8.4 \\
\hline Pushing or pulling loads & 15.5 & 0.0 & 15.6 & 0.0 \\
\hline
\end{tabular}

weeks. We used interval censoring, meaning that we did not consider people who in a given week received any other social benefit than sickness absence compensation to be at risk. This includes sickness absence spells of less than eight weeks. We censored people who died, emigrated, or retired. The total risk time for men was therefore not $78 \times 2587=201786$ possible weeks but 178904 weeks (88.7\%) and the total risk time for women was not $78 \times 2446=190788$ possible weeks but 157132 weeks $(82.4 \%)$.

\section{Long term sickness absence}

We defined the outcome of this study, long term sickness absence, as receiving sickness absence compensation for a period equalling eight consecutive weeks or more during the follow-up period from 1 January 2001 to 30 June 302002.

\section{Physical work environment risk factors}

We measured physcial risk factors in the work environment with 11 questions combined into five indices. Three indices measured uncomfortable work positions: extreme bending or twisting of the neck or back, work with arms lifted or hands twisted, and working mainly standing or squatting. ${ }^{17}$ Two indices measured physical workload in terms of lifting or carrying loads, and pushing or pulling loads. The index for lifting or carrying loads was constructed as the mean of two questions (the values in parentheses show the value assigned to the response options according to an index scale score range of 0-100): "How much of your working hours do you carry or lift things/people?" The response options were "Almost all working hours" (100), "Three quarters of working hours" (75), "Half of working hours" (50), "A quarter of working hours" (25), "Seldom" (6), "Never" (0); and "What does the load you carry normally weigh?' with response options "Less than 3 kg" (2.5), "3-10 kg” (10.8), "11-29 kg” (33.3), "30-49 kg" (65.8) and "50 kg or more" (100). If respondents answered "Never" to the former question we coded the latter question 0 . The index for pushing or pulling was constructed as the mean of two questions: "How much of your working hours do you push or pull loads?" with response options "Almost all working hours" (100), "Three quarters of working hours" (75), "Half of working hours" (50), "A quarter of working hours" (25), "Seldom" (6), "Never" (0); and "How do you usually experience pushing or pulling loads?" with the response options "Very heavy" (100), "Heavy" (75), "Neither heavy nor light" (50), "Light" (25) and "Very light" (0). If respondents answered "Never" to the former question we coded the latter question 0 .

All index scores range from 0 to 100 . Mean and median scores for female and male employees are shown in table 1.

\section{Covariates}

Sociodemographic characteristics

The study includes data on sex and baseline age of the individual employee. We divided education into three categories of school education: nine years or less, 10 years, or high school. We used two variables to categorise family status: the number of children living at home (four categories: none, one, two, or three or more children) and cohabitation (living with a partner or not). If a participant reported having had a disease diagnosed by a doctor for six months or longer, we classified him or her as having a chronic disease.

\section{Health behaviour}

We divided smoking status into three categories: current smokers, previous smokers, and never smokers. We calculated body mass index by dividing weight in kilograms with squared height in metres.

We divided alcohol consumption into three categories according to weekly consumption: non-drinkers, moderate drinkers (1-14 units for women or 1-21 units for men), or heavy drinkers who consumed more than 14 (for women) or 21 (for men) units of alcohol the preceding week. In this study, 1 unit of alcohol is defined as $12 \mathrm{~g}$ of pure alcohol.

Furthermore, we classified the population in four groups according to leisure time physical activity: 0-2 hours per week, 2-4 hours per week, more than 4 hours per week or heavy, or more than 4 hours per week and heavy.

\section{Psychosocial risk factors in the work environment}

Psychosocial risk factors in the work environment were measured with 42 items combined into 13 scales. The scales measured decision authority, skill discretion, quantitative demands, emotional demands, demands of hiding emotions, job insecurity, social support from colleagues and supervisor, management quality, role conflicts, reward in work, meaning of work, predictability in work, and conflicts at work. The scale items, response categories, and scale characteristics measured on the specific study population are described elsewhere. ${ }^{16}$

We measured intensity of quantitative demands with a single question: "Do you have to work very fast?" The response options were: "Always," "Often," "Sometimes," "Seldom," or "Never/ hardly ever."

\section{Analysis}

To examine the relation between physical work environment exposures at baseline and the onset of long term sickness absence during follow-up, we used Cox regression to analyse the data. We calculated hazard ratios and 95\% confidence intervals per standard deviation change in scores on the indices measuring work environment. We standardised the indices before entering the Cox regression analysis. We adjusted all proportional hazards models for age, education, chronic disease, family status, health behaviour, and psychosocial exposures in the work environment. We analysed the interaction between psychosocial and physical risk factors by introducing interaction terms between significant $(\mathrm{P}<0.05)$ physical and psychosocial risk factors in the work environment. We used SAS 8.02 (SAS Institute, Cary, NC, 2001).to analyse our data. 
Table 2 Risk of an increase of 1 standard deviation on each physical risk factor index

\begin{tabular}{|c|c|c|c|c|}
\hline \multirow{2}{*}{ Risk factor } & \multicolumn{2}{|c|}{ Female employees $(n=2446)$} & \multicolumn{2}{|c|}{ Male employees $(\mathrm{n}=2587)$} \\
\hline & Hazard ratio $(95 \% \mathrm{Cl})$ & $P$ value & Hazard ratio $(95 \% \mathrm{Cl})$ & $P$ value \\
\hline Extreme bending or twisting of neck or back & 1.21 (1.05 to 1.40$)$ & 0.01 & 1.41 (1.21 to 1.63$)$ & 0.00 \\
\hline Working with arms lifted or hands twisted & 1.05 (0.89 to 1.23$)$ & 0.57 & $1.15(0.97$ to 1.33$)$ & 0.11 \\
\hline Working mainly standing or squatting & 1.31 (1.10 to 1.56$)$ & 0.00 & 1.54 (1.29 to 1.84$)$ & 0.00 \\
\hline Lifting or carrying loads & 1.27 (1.08 to 1.49$)$ & 0.00 & 1.51 (1.29 to 1.76) & 0.00 \\
\hline Pushing or pulling loads & $1.20(1.04$ to 1.39$)$ & 0.02 & 1.28 (1.08 to 1.52$)$ & 0.00 \\
\hline
\end{tabular}

Hazard ratios adjusted for age, education, family status, chronic disease, health behaviour, and psychosocial exposures.

\section{Results}

A total of 348 participants (6.9\%) experienced long term sickness absence during follow-up. Of these 194 (55.7\%) were women and $154(44.3 \%)$ were men. For female employees, the risk of long term sickness absence was significantly increased $(\mathrm{P}<0.05)$ when exposed to extreme bending or twisting of neck or back, working mainly standing or squatting, lifting or carrying loads, and pushing or pulling loads.

For male employees, exposure to extreme bending or twisting of neck or back, working mainly standing or squatting, lifting or carrying loads, and pushing or pulling loads were significant risk factors for onset of long term sickness absence (table 2).

For female employees, three psychosocial factors were significant. We tested the $3 \times 4=12$ possible interactions between these and the physical factors.

In three of the 12 combinations, we found a significant interaction effect (departure from multiplicativity; $\mathrm{P}<0.05$ ). The effect of an increase of one standard deviation on working mainly standing or squatting was a $40 \%$ increase in risk for long term sickness absence and the effect of an increase in role conflict was a $21 \%$ increase in risk for long term sickness absence. The combined effect was not $1.40 \times 1.21=1.69$ but $1.40 \times 1.21 \times 1.17=1.98$ (table 3$)$.

The combined effects of the two remaining significant combinations could be calculated accordingly to a hazard ratio of 1.53 for simultaneous exposure to extreme bending or twisting of neck or back and high emotional demands, and the combination of lifting or carrying loads and role conflicts yielded a hazard ratio of 1.77 .

For male employees two psychosocial factors were significantly associated with onset of long term sickness absence $(\mathrm{P}<0.05)$. We tested the $2 \times 4=8$ possible interactions between these and the physical factors. We found no significant interactions.

Table 3 Estimated risks in three models including significant interactions between effects of physical and psychosocial risk factors in the work environment on long term sickness absence for 2446 female employees

\begin{tabular}{lcc} 
Risk factor or interaction term & Hazard ratio (95\% $\mathbf{~ I )}$ & P value \\
\hline Extreme bending or twisting of neck or back & $1.18(0.99$ to 1.39$)$ & 0.06 \\
\hline High emotional demands & $1.14(0.98$ to 1.34$)$ & 0.09 \\
\hline $\begin{array}{l}\text { Extreme bending or twisting of neck or back×high } \\
\text { emotional demands }\end{array}$ & $1.14(1.01$ to 1.28$)$ & 0.03 \\
\hline Working mainly standing or squatting & $1.40(1.18$ to 1.65$)$ & 0.00 \\
\hline Role conflict & $1.21(1.04$ to 1.40$)$ & 0.01 \\
\hline Working mainly standing or squatting $\times$ role conflict & $1.17(1.01$ to 1.37$)$ & 0.04 \\
\hline Lifting or carrying loads & $1.23(1.04$ to 1.45$)$ & 0.01 \\
\hline Role conflict & $1.17(1.00$ to 1.36$)$ & 0.05 \\
\hline Lifting or carrying loads $\times$ role conflicts & $1.15(1.03$ to 1.45$)$ & 0.01 \\
\hline
\end{tabular}

Adjusted for age, education, family status, chronic disease, and health behaviour.

\section{Discussion}

The physical work environment defined in terms of uncomfortable working positions, lifting or carrying loads, and pushing or pulling loads increased the risk of onset of long term sickness absence among female and male employees. For female employees, the negative effects of poor physical work conditions were further increased if the psychosocial work conditions were also poor.

\section{Comparison with other studies}

In a review paper by Allebeck and Mastekaasa, the authors claim to find limited scientific evidence for an association between physical working conditions and sickness absence, possibly for ergonomic load in particular. ${ }^{2}$ This is contrary to conclusions made by other reviewers on the same topic. ${ }^{18}$ Nevertheless, our study supports earlier findings showing associations between uncomfortable working positions, physical workload, and increased risk of sickness absence. Trinkoff et al found awkward head and arm postures to predict sickness absence in a study among 3727 certified nurses. ${ }^{11}$ In a study of 42508 employees from the metal processing and retail trade followed for three years, Boedeker found sick leave related to hypertension, ischaemic heart diseases, ulcer, neurotic disorders, or work accidents to be most common in employees exposed to physical demands and low job control. ${ }^{10}$ Our study overcomes some of the methodological shortcomings pointed out by Allebeck and Mastekaasa with regard to design. Both the studies by Trinkoff et al and Voss et al feature cross sectional designs, ${ }^{911}$ whereas ours has a longitudinal design.

\section{Measuring physical exposures}

When reviewing the literature on occupational risk factors for sickness absence, we found no gold standard for measuring physical exposures. Some studies adapt a broad understanding of physical work environment, additionally encompassing exposures to, for example, dust and unpleasant temperature. ${ }^{319}$ Others address specific ergonomic exposures as captured in the measures for the physical risk factor in the work environment that we used in this study. ${ }^{9-11}$ The studies by Boedeker and Trinkoff et al differ in terms of measurement method: The study by Trinkoff et al was based on employees' self reported assessment of exposure, ${ }^{11}$ whereas the study by Boedeker featured an external expert evaluation of exposures. ${ }^{10}$ This raises the discussion of so called subjective and objective measures. In relation to our study, the issue of subjectivity of the measurement of physical exposures is considered to be less relevant because of the longitudinal design allowing (employee reported) exposure assessment before (register recorded) onset of long term sickness absence. As our baseline measurements were questionnaire based and we used register data to establish our outcome, the possible common method variance and the related positive bias is eliminated. ${ }^{20}{ }^{21}$ Furthermore, the items included in the indices in this study do not ask about complaints concerning specific 


\section{What is already known on this topic}

Sickness absence is caused by a variety of factors, including working conditions

Although long term sickness absence is costly to society, its occupational causes have remained uncertain

\section{What this study adds}

Exposure to uncomfortable work positions and physically heavy work increased the risk of long term sickness absence for both men and women

The negative effects of physical exposures were increased for women also exposed to certain psychosocial factors

work situations like some other studies ${ }^{9}$ and have proved as strong predictors in other longitudinal studies using different definitions of, and data sources for, sickness absence. ${ }^{17}$

\section{Conclusions}

When a broad array of potentially confounding covariates related to sociodemography, chronic disease, health behaviour, and psychosocial work environment risk factors are included, this study shows a potential for reducing long term sickness absence through adapting work postures straining the neck and back, reducing the risk of work done standing or walking, and reducing the risk associated with handling loads. Simultaneous intervention targeting two psychosocial risk factors in the work environment-role conflict and emotional demands-might increase the effect of interventions towards physical risk factors among female employees owing to interaction effects.

Contributors: TL, ML, KBC, and UB contributed to the initiation of the study, study design, conduct of the study, statistical analysis, and preparation of the manuscript. EV contributed to conduct of the study, data management and preparation of the manuscript. TL is guarantor.

Funding: None.

Competing interests: None declared.

Ethical approval: The study has been notified to and registered by Datatilsynet (the Danish Data Protection Agency). According to Danish law, questionnaire and register based studies do not need approval by ethical and scientific committees, nor informed consent.

1 Krause N, Lund T. Return to work. In: Barling J, Frone M, eds. The psychology of workplace safety. Washington, DC: American Psychological Association, 2004.

2 Allebeck P, Mastekaasa A. Risk factors for sickleave-general studies. Scand J Public Health 2004;32(suppl 63):49-108
3 Blank N, Diderichsen F. Short-term and long-term sick-leave in Sweden: relationships with social circumstances, working conditions and gender. Scand J Soc Med 1995;23:265-72

4 Henderson M, Glozier N, Elliott KH. Long term sickness absence. BMJ 2005;330:802-3.

5 Alexanderson K, Hensing G. More and better research needed on sickness absence. Scand J Public Health 2004;32:321-3.

6 Alexanderson K, Norlund A. Swedish Council on Technology Assessment in Health Care (SBU). Chapter 12. Future need for research. Scand J Public Health 2004;32(suppl 63):256-8.

7 The Government. Det gør vi ved sygefravaret [Action Plan on sick leave]. Copenhagen: Danish Ministry of Employment, 2003.

8 Hoogendoorn WE, Bongers PM, de Vet HC, Ariens GA, van Mechelen W, Bouter LM. High physical work load and low job satisfaction increase the risk of sickness absence due to low back pain: results of a prospective cohort study. Occup Environ Med 2002;59:323-8.

9 Voss M, Floderus B, Diderichsen F. Physical, psychosocial, and organisational factors relative to sickness absence: a study based on Sweden Post. Occup Environ Med 2001;58:178-84.

10 Boedeker W. Associations between workload and diseases rarely occurring in sickness absence data.J Occup Environ Med 2001;43:1081-8.

11 Trinkoff AM, Storr CL, Lipscomb JA. Physically demanding work and inadequate sleep, pain medication use, and absenteeism in registered nurses. J Occup Environ Med 2001;43:355-63.

12 Houtman IL, Bongers PM, Smulders PG, Kompier MA. Psychosocial stressors at work and musculoskeletal problems. Scand J Work Environ Health 1994;20:139-45.

13 Väänänen A, Toppinen-Tanner S, Kalimo R, Mutanen P, Vahtera J, Peiró JM. Job characteristics, physical and psychological symptoms, and social support as antecedents of sickness absence among men and women in the private industrial sector. Soc Sci Med 2003;57:807-24

14 Devereux JJ, Vlachonikolis IG, Buckle PW. Epidemiological study to investigate potential interaction between physical and psychosocial factors at work that may increase the risk of symptoms of musculoskeletal disorder of the neck and upper limb. Occup Environ Med 2002;59:269-77.

15 Burr H, Bjorner JB, Kristensen TS, Tuchsen F, Bach E. Trends in the Danish work environment in 1990-2000 and their associations with labor-force changes. Scand J Work Environ Health 2003:29:270-9.

16 Lund T, Labriola M, Kristensen KB, Bültmann U, Villadsen E, Burr H. Psychosocial work environment exposures as risk factors for long-term sickness absence among Danish employees: results from DWECS/DREAM. J Occup Environ Med 2005;47:1141-7.

17 Lund T, Csonka A. Risk factors in health, work environment, smoking status, and organizational context for work disability. Am J Ind Med 2003;44:492-501.

18 Krause N, Frank JW, Dasinger LK, Sullivan TJ, Sinclair SJ. Determinants of duration of disability and return-to-work after work-related injury and illness: challenges for future research. Am J Ind Med 2001;40:464-84.

19 Vahtera J, Kivimaki M, Pentti J, Theorell T. Effect of change in the psychosocial work environment on sickness absence: a seven year follow up of initially healthy employees. Epidemiol Community Health 2000;54:484-93.

20 Spector PE. Method variance as an artifact in self-reported affect and perceptions of Spector PE. Method variance as an artifact in self-reported affect
work: myth or significant problem? J Appl Psychol 1987;72:438-43.

21 Williams LJ, Cote JA, Buckley MR. Lack of method variance in self-reported affect and perceptions at work: reality or artifact? J Appl Psychol 1989;74:462-8.

(Accepted 24 December 2005)

doi 10.1136/bmj.38731.622975.3A

National Institute of Occupational Health, Lerso Parkallé 105, DK-2100 Copenhagen, Denmark

Thomas Lund researcher

Merete Labriola researcher

Karl Bang Christensen statistician

Ute Bültmann researcher

Ebbe Villadsen data manager

Correspondence to: T Lund tl@ami.dk 